\title{
Tecno-indigenismo. Martín Chambi y el duelo de las imágenes
}

\author{
MÓNICA BERNABÉ Universidad Nacional de Rosario - CONICET, Argentina / monicabernabe02@gmail.com
}

\section{Resumen}

La práctica fotográfica de Martín Chambi supone algo más que la realización de fotografías admirables. Es una operación de transculturación en el marco de una disputa semiótica por autoridad y legitimidad frente a la empresa de apropiación colonial que desde mediados del XIX venía realizando el registro cientificista de las regiones conquistadas gestionado por geógrafos, antropólogos, arqueólogos, misioneros, expedicionarios y empresarios. El contrapunto en el arte de Chambi se desata por el plus estético y afectivo con que retrata un territorio y produce una localidad en tensión con las demandas de los prototipos primitivistas del modernismo internacional. Habrá que cuidarse de reducir el análisis de las imágenes a sus temas, conceptos, esquemas clasificatorios, tipos. No nos proponemos explicarlas sino dar cuenta de los duelos, los desgarramientos y las tensiones que las atraviesan. Se trata de leer en ellas su carácter crítico para poder distinguir -en los mudos documentos de archivos- las voces inaudibles, los reclamos perdidos, el desafío al patrón logocéntrico que descansa en la primacía de la palabra sobre la imagen. Desde esta perspectiva, lejos de ser ilustración o documento, la fotografía dialoga de manera singular con la masa discursiva agrupada bajo el rótulo de indigenismo.

Palabras clave: imágenes / duelo / indigenismo / Martín Chambi / fotografía

\section{Tecno-indigenism. Martín Chambi and the duel of the images}

Abstract

The photographic practice of Martín Chambi supposes something more than the accomplishment of admirable photographs. It is a transculturation operation in the framework of a semiotic dispute for authority and legitimacy against the colonial appropriation company that since the mid-nineteenth was making the scientific registration of the conquered regions managed by geographers, anthropologists, archaeologists, missionaries, expeditions and entrepreneurs. The counterpoint in the art of Chambi is unleashed by the aesthetic and affective plus with which it portrays a territory and produces a locality in tension with the demands of the primitivist prototypes of international modernism. We will have to take care to reduce the analysis of the images to their themes, concepts, classification schemes, types. We do not propose to explain them but to give an account of the duels, the tears and the tensions that cross them. The aim is to read their critical character in order to distinguish inaudible voices, lost claims, the challenge to the logocentric pattern that rests on the primacy of the word over the image. From this perspective, far from being an illustration or a document, photography dialogues in a singular way with the discursive mass grouped under the label of indigenismo.

Key words: images / duel / indigenismo / Martín Chambi / photography

Recibido: 28/9/2018. Aceptado: 12/10/2018

Para citar este artículo: Bernabé, Mónica (2018). Tecno-indigenismo. Martín Chambi y el duelo de las imágenes. El taco en la brea, 8 (junio-noviembre), 66-75. Santa Fe, Argentina: UNL. DOI: 10.14409/tb.v1i8.7757 
Palavra, literatura e cultura es el título bajo el cual Ana Pizarro editó, en San Pablo, una monumental compilación donde reúne trabajos de destacados especialistas en literatura latinoamericana que examinan el estado de la cuestión del campo disciplinar a fines del siglo XX. El inicio de cada uno de los artículos o entradas, a la manera de un separador, presenta una imagen ilustrativa del tema o período que trata. Para la entrada correspondiente al indigenismo andino, escrita por Antonio Cornejo Polar, los editores optaron por reproducir una fotografía de Martín Chambi. Reconocemos la imagen que en la edición de Pizarro lleva como título «Propietario de una hacienda con sus trabajadores en Perú, hacia 1945 (Foto de Martín Chambi)». El artículo de Cornejo Polar nada dice del arte de Chiambi ni de los Q'Orilasos ${ }^{2}$ que allí retrató, tampoco de la función que cumplió la fotografía en el marco del movimiento que estudia. Así, la imagen queda supeditada al enunciado que la acompaña, esto es, dar evidencias de un mundo que se divide en dos: el propietario (el hombre ocupa el centro de la escena y viste a la manera burguesa con corbata, camisa blanca y traje negro) y los trabajadores (el resto de las personas que rodean al hombre y visten con ropa de fajina). El pie de imprenta con que la fotografía de los Q'Orilasos fue editada en esta oportunidad, mucho le debe al sociologismo, es decir, a cierta vulgata de la disciplina que ejerció la hegemonía en el análisis del movimiento. Resulta curioso que la noción de «trabajador» aquí sea empleada para referir a los grupos subalternos de una región donde las poblaciones habían sido incorporadas al capitalismo bajo formas no-salariales, en particular, en términos de servidumbre. ${ }^{3}$

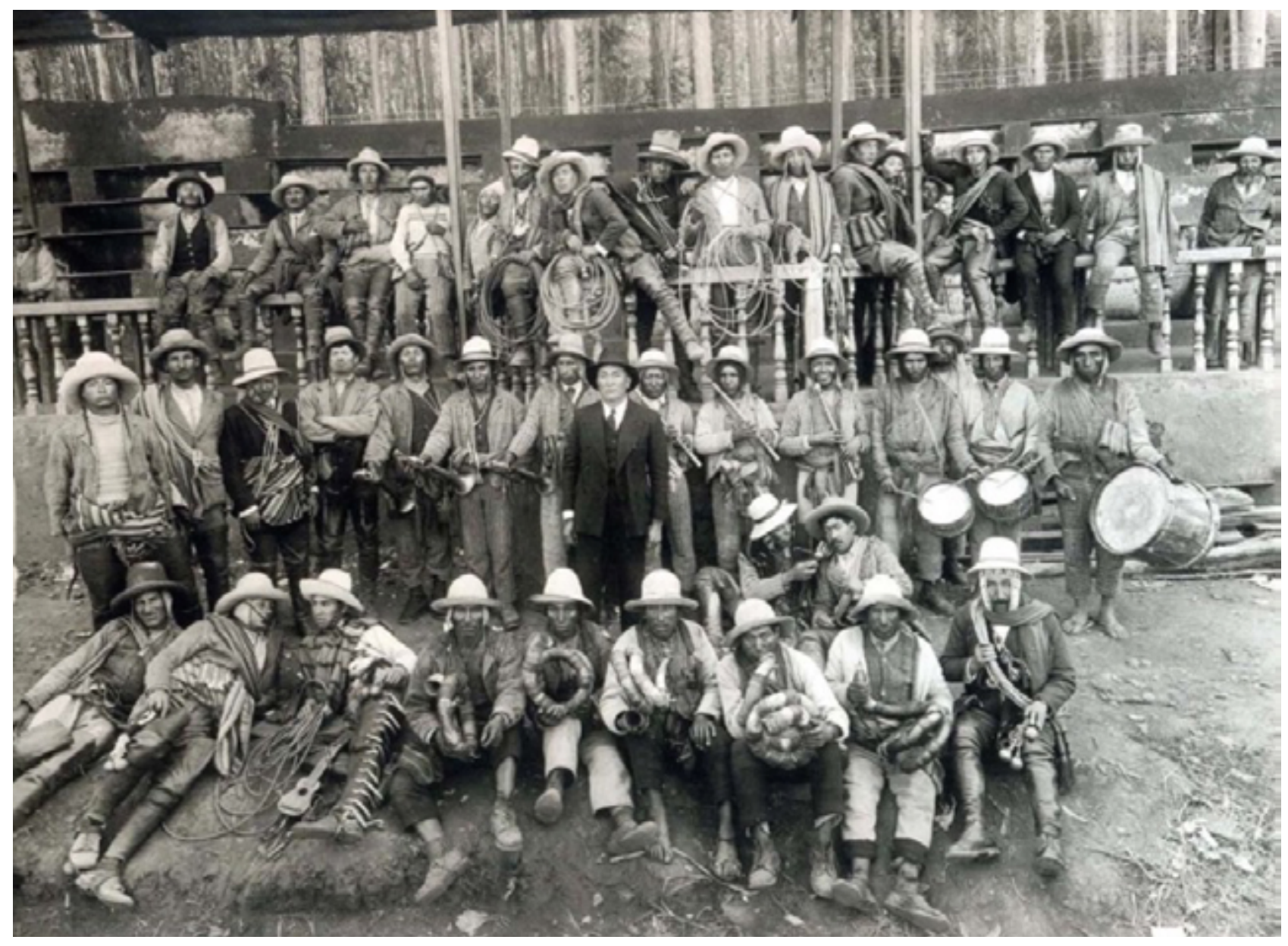

Q’Orilasos de Chumbivilcas. Fotografía de Martín Chambi (1944) 
Sin embargo, en su mudez, la imagen parece resistir a las clasificaciones. Los Q'Orilasos con sus característicos ponchos, fajas, qarawatana, espuelas, kirkinchu y guitarras siguen allí como restos significantes. La escenografía, que pareciera haber sido montada con afición barroca, ofrece la ocasión para una serie de preguntas desde la frontera de las disciplinas, espacio singular y productivo que viene rediseñando - desde hace un tiempo- los objetos de estudios de la crítica literaria latinoamericana: ¿qué estatuto asume la fotografía en el marco de las narrativas andinas del siglo XX?, ¿cómo leer el indigenismo de/en la fotografía? En definitiva, ¿cuál es la relación entre indigenismo y fotografía?, ¿y entre indigenismo y tecnología? Sin desatender a la tensión dialéctica entre lo que vemos y lo que nos mira, nos proponemos argumentar sobre las heterogeneidades, las temporalidades múltiples, los detalles significantes, los montajes escénicos con el deseo de circular entre el hecho objetivo del pasado y la potencia prospectiva del archivo. Desde esta perspectiva, la fotografía de Martín Chambi, lejos de funcionar como ilustración o documento, dialoga de manera singular con la inmensa masa discursiva agrupada bajo el rótulo de indigenismo.

Y el retorno de Chambi, hacia fines del siglo veinte, impulsa también otros interrogantes que, si bien no serán resueltos en este trabajo, merecen ser planteados a los fines de diseñar el contexto de su exhumación: ¿por qué, en un volumen de crítica literaria publicado hacia mediados de los noventa, Martín Chambi es elegido para «ilustrar» al indigenismo?, ¿cuándo fue que se volvió un artista representativo, es decir, cómo se tramitó el ingreso de su obra al panteón de la cultura nacional e internacional? En el centro de esta cuestión, deben observarse los crecientes procesos de institucionalización y museificación de objetos y obras pertenecientes a zonas y prácticas de la cultura olvidadas o marginadas por los relatos hegemónicos. Las circunstancias de internacionalización de Chambi y de su entrada al museo, o para decirlo con mayor precisión, de su triunfo en el MOMA en 1979, obedecen a las políticas de archivo y de archivación que ordenan y legitiman el relato del modernismo, es decir, ese dispositivo centralizador del arte occidental que Hal Foster denominó «momaísmo» a partir del análisis del lugar que ocupa Les desmoiselles de Avignon y la transgresión con la que Picasso mediatiza lo primitivo en nombre de Occidente.

Comencemos por consignar el dato extemporáneo del «descubrimiento»: en la narrativa primitivista del mercado internacional del arte, tributaria de la colonialidad del poder, la obra de Chambi es leída como una excepción, rara avis florecida en un medio arcaico o atrasado. Se enfatiza su condición indígena, se refiere a la pobreza de sus padres — quechua-hablantes y analfabetos- para, finalmente, deshistorizar su legado. De este modo, Chambi representa un enigma que se resuelve por el lado del heroísmo de un campesino que aprendió la técnica de la fotografía por casualidad. En fin: un primitivo que se volvió primitivista. La operación consiste en sustraerlo de la historia local para volverlo universal y capturarlo para el modernismo hegemónico; borrar la coyuntura de su emergencia para configurarlo como genio.

Desandar esta trama supone reinsertar a Chambi a su coyuntura, a las geografías de los modernismos latinoamericanos donde se desarrollaron formas alternativas y relatos diferenciales de la narrativa maestra del modernismo europeo. En este marco, Chambi deja de ser un caso para recuperar su carácter de productor en relación con otros muchos productores que, en una región peculiar, articularon una manera de hacer fotografías. Chambi fue un artesano que desde un saber específico potenció su imaginación técnica para forjar su figura de artista. Paradójicamente, su trabajo como fotógrafo social al tiempo que como reportero gráfico, le permitió obtener una relativa autonomía como artista en un campo precario para el que no hay mejor descripción que 
el preciso y justo verso de Vallejo: «campo intelectual de cordillera/ con religión, con campo, con patitos». Chambi, entonces, no fue una figura solitaria ni su arte, una excepción.

Dos factores concomitantes, tecnología y el archivo, trazan las líneas críticas que permiten retornar al indigenismo para revisar su conceptualización. Su ambigüedad se acrecienta en el juego de sus variaciones: incaísmo, indianismo, andinismo, neo-indigenismo, cholismo, mestizaje e hibrideces varias. Carlos Franco, a principios de los noventa, ponía en dudas su existencia: «El indigenismo - decía - es una fórmula sumaria, equívoca, encubridora» (53). Advertía sobre el peligro de reducir en el simplismo de una fórmula la complejidad, la diversidad y los cambios de los procesos culturales.

La crítica del indigenismo habitualmente separa su objeto en dos campos de estudio: por un lado, el indigenismo de los postulados políticos y de las demandas de justicia social que es abordado mayoritariamente por historiadores, sociólogos y antropólogos. Por el otro, el indigenismo de las prácticas artísticas y literarias, una zona que atienden, en general, las humanidades. A esta zona, Mirko Lauer le asignó un número, el 2, asumiendo la idea del carácter derivado del indigenismo artístico y literario. ${ }^{4}$ Es decir, un presupuesto según el cual, la reivindicación política funciona como marco general de las prácticas artísticas. Sin embargo, esta división entre arte y política, que puede justificarse por motivos heurísticos, termina por articular causas y efectos de un fenómeno cuya diversidad es mucho más que dos. En la larga historia de los movimientos de pueblos, los indigenismos constituyeron una forma de figuración de un tiempo y un espacio que permitió - para decirlo en las palabras de Didi-Huberman — la emergencia de una parcela de humanidad despojada. El indigenismo andino de principios de siglo XX fue una manera específica de figurar a los otros, y también fue una forma de exponerlos. Reparar en los pueblos expuestos, entonces, implica examinar el doblez, el pliegue de esa exposición. Cuando los pueblos son objeto de exposición reiterada en imágenes estereotipadas es porque están, precisamente, expuestos a la desaparición. El indigenismo, en este sentido, es la forma específica en que una serie de pueblos - en trance de desaparición - comienzan a aparecer, a ser figurados en la política y en el arte bajo la abstracción deformadora de un tipo, de una fórmula, de una representación altamente codificada.

Esa fórmula equívoca de la que habla Franco retorna - y seguirá retornando — en la medida en que persistan los reclamos de justicia y de reparación por el despojo. Revisar el carácter tecnológico de indigenismo cusqueño de los años veinte propone un modo de explorar el archivo fuera de la lógica bipolar con la que sigue entrampado el análisis desde las oposiciones entre arte y política; indigenista e indígena; español e indio; arcaico y moderno. La relación entre indigenismo y tecnologías lleva a pensar en los términos de su emergencia en el sentido en que Arguedas lo planteaba en sus ensayos de mediados de siglo: la modificación de la vida cotidiana de los pueblos y las intervenciones en el paisaje serrano a partir de la tecnologización de la comunicación y del transporte, del espectáculo y el ocio, tan influyentes en las industrias del turismo y la cultura. La experiencia tecnológica puede haber sido, como intuye Huyssen, el acontecimiento «que disparó la chispa de la vanguardia». Y cuando decimos vanguardia hacemos referencia al sentido que la palabra tenía desde fines del siglo XIX, esto es, un concepto que no estaba limitado a la esfera del arte sino que se usaba para referirse a la unidad del radicalismo político con el artístico en lucha por transformar la vida y, de ese modo, accionar por la revolución. Hace cien años, la Revolución rusa aunaba política y arte en el culto de la tecnología en un país agrario y prácticamente sin 
industrias, en este punto muy similar a como era el Perú. Ningún rincón del mundo, por más apartado que este se encuentre, quedó a salvo del impacto de las primeras formas de lo audiovisual como lo demuestran las crónicas de José Carlos Mariátegui sobre las películas de Chaplin o la mirada cinematográfica con la que Luis E. Valcárcel proponía «localizaciones» para filmes futuros en los mismos lugares donde los Q'Orilasos que fotografiaba Chambi podrían exhibir sus destrezas ecuestres:

¡Cuántos Facundo Quiroga saldrán del gauchismo chumbivilcano! La novela recogerá un día en el Perú las aventuras de los «ch'uchus» ladrones. Entonces se van a quedar atrás los filmes del Far West. Vengan los operadores de William Fox a recoger los episodios inverosímiles de la vida del indio a caballo. (Tempestad en los Andes:93)

Decíamos que la relación entre indigenismos y tecnología se vuelve productiva a los fines de desarmar las oposiciones con las que operan los esencialismos. A esa relación hay que sumarle las lógicas de archivo, sus leyes de ordenación y del entramado entre aquello que es digno de recordación y aquello que permanece anclado en el olvido. Tal vez involuntariamente, la edición de Pizarro, al aproximar la fotografía de los Q'Orilasos y el ensayo sobre narrativa indigenista de Cornejo Polar puso en escena una colisión de archivo conectando materialidades que no podían ser conectadas, es decir, al cruzar el corpus clásico de la biblioteca letrada (que es el eje del trabajo de Cornejo Polar) con la inconmensurabilidad del archivo del siglo XX (desde donde emergen las fotografías de Chambi). Este contrapunto de biblioteca y archivo desmantela las tradicionales jerarquías que dividen al indigenismo entre los intelectuales universitarios que hablaron en nombre de las masas desposeídas y los productores culturales que, provenientes de los estratos más humildes de la población, conformaron una elite plebeya dispuesta a conquistar los espacios vacantes emergentes entre las grietas que la incipiente industria cultural perpetraba en los muros de la ciudad letrada. Y los arietes con los que arremetían descansaban en la progresiva profesionalización de sus prácticas artísticas estrechamente ligadas a las nuevas tecnologías. Las excelentes investigaciones de Jorge Coronado, Javier García Liendo, Zoila Mendoza exploran ese archivo audiovisual y demuestran con eficacia cómo, en las primeras décadas del siglo XX, se forjaron indigenismos desde abajo al ritmo de las rebeliones campesinas, las canciones populares, los espectáculos teatrales y los nuevos oficios como los del reportero gráfico, una actividad que, para dar un ejemplo, desempeñó Martín Chambi desde 1918 como lo demostró, recientemente, la investigación de Herman Schwarz al indagar sobre los alcances del fotoperiodismo, una especialidad que probablemente haya sido crucial no sólo en la formación de Chambi, sino en la configuración de los indigenismos metropolitanos, tanto el limeño como el de las restantes capitales de América Latina.

Ciertas formulaciones teóricas de la noción de archivo permiten revisar el indigenismo y la crítica del indigenismo. En primer lugar, si el archivo foucaultiano no sólo remite a las palabras, y va más allá de determinar los enunciados detrás o debajo de las frases es porque, como sostiene Deleuze, ofrece una oportunidad de destacar el gesto del hablo en lugar del pienso. En este sentido, el archivo supone otro gesto mayor, inconmensurable, que apunta al veo y escucho (Morey). En segundo lugar, cuando Derrida aproxima archivo y psicoanálisis, orienta la búsqueda hacia lo reprimido, lo suprimido, ocultado, desviado. El archivo también es aquello que se guarda o se oculta, aquello que no se ve o no se quiere ver pero que resiste. Seguir estas conjeturas supone sostener que la estructura 
técnica del archivo determina la estructura del contenido archivable tanto en su surgir como en su porvenir. Vale decir: los modos de archivación de lo indígena producen diferentes versiones del indigenismo. Así entendido, el indigenismo deja de ser registro de identidades tradicionales o expresión de lo local (nacional o regional), tampoco se consuma como colección de narrativas, documentos y monumentos atesorados y guardados. En sintonía con el carácter prospectivo del archivo, el indigenismo se vuelve zona de proyecto, identidad en proceso y objeto de prácticas diversas.

Entonces, desde esta perspectiva, cuando el archivo mismo contiene el germen de su propia destrucción podemos interrogar por los comienzos: ¿qué está primero?, ¿la fotografía o el indigenismo? La pregunta no es menor, mejor aún, podemos decir que la pregunta es decisiva porque el indigenismo parece estar enraizado en la médula de la empresa fotográfica. ¿Cuál es el poder archivante de la fotografía en el caso del indigenismo? Sabemos, porque ha sido lo suficientemente estudiada, de la relación entre fotografía y antropología cuando, a mediados del siglo XIX, ambas prácticas se complementaron en la tarea de construir subjetividades y cuerpos y de establecer patrones de jerarquización entre pueblos y razas. En este período inicial, la empresa fotográfica colonial proveía materiales a las metrópolis a la manera de datos brutos, una suerte de extractivismo cultural que satisfacía una doble demanda: el deseo primitivista del mercado del arte y la ambición clasificatoria de las ciencias naturales y del hombre. Y de algún modo funcionaban como metáfora del poder, apropiándose del tiempo y el espacio de los individuos estudiados. Recordemos, una vez más, la hipótesis de Didi-Huberman: los pueblos son expuestos cuando están a punto de su desaparición. La fotografía, de este modo, emerge como prueba testimonial de la presencia in situ del antropólogo y el carácter verídico de su relato: funcionó como documento de autenticación. ${ }^{5}$

Los excelentes trabajos de Deborah Poole giran sobre este tema al describir el proceso de formación de una modernidad diferencial en sintonía con la emergencia de una comunidad de fotógrafos en la región surandina al comienzo del siglo XX. El primer estudio fotográfico en Cusco fue fundado en la década de 1890 por una congregación de misioneros evangélicos ingleses que utilizaban las fotografías de indios con harapos para recolectar dinero en Inglaterra (Poole 1991:129). El dato inscribe a la historia de la fotografía en los Andes como parte de la empresa colonial puesto que también aquí adopta el formato cartes de visite para reproducir «tipos de indios», mercancía que fue comercializada con éxito en las capitales europeas. Poole también demuestra cómo la fotografía fue tecnología crucial para Hiram Bingham en su expedición de «descubrimiento» de Machu Picchu. El explorador norteamericano creó un archivo enorme (11.ooo negativos) que funcionó como una forma de apropiación y de legitimación de una empresa colonial que el mismo Valcárcel junto con otros intelectuales indigenistas impugnaron desde 1915.

Desde la inconmensurabilidad del archivo y su relación con la biblioteca, el indigenismo del veinte se configura por una red de relaciones entre documentos y acontecimientos: ensayos, novelas, polémicas, imágenes pictóricas, guías turísticas, crónicas periodísticas, reportajes de fotoperiodismo, manifiestos y revistas de la vanguardia, cancioneros populares, descubrimientos arqueológicos, demandas judiciales, protestas campesinas a través de diversas tecnologías: fotografía, radiofonía, telégrafo, correo postal, vías férreas, aviación, cinematografía, imprenta. La lista es heterogénea pero contiene algunos elementos que invierten la idea general que se tiene de las obras indigenistas (plásticas y narrativas) según la cual la producción y consumo se efectúa en un universo distinto al del referente predicado (Cornejo Polar:17). La fotografía, al igual que el cancionero popular, es producción de localidad y localidad de la producción —-para decirlo en los 
términos de Appadurai-, funda paisajes serranos, escenas urbanas, retratos de estudio con telón pintado, ambientaciones arquitectónicas múltiples (haciendas, obras viales, conventos, escuelas, obradores, teatros, museos, casas particulares, despachos jurídicos, iglesias) para un ámbito de circulación diverso ya que, mientras respondía a una demanda turística alentada por la incipiente industria cultural de tinte regional en sintonía con los medios gráficos nacionales e internacionales, creaba una demanda local que funcionó con una dinámica propia posibilitando la emergencia de nuevos consumidores. ${ }^{6}$

\section{II}

Las prácticas fotográficas de Chambi suponen algo más que la realización de fotografías admirables. Son una operación de transculturación en el marco de una disputa semiótica por autoridad y legitimidad frente a la empresa de apropiación colonial que, como ya vimos, desde mediados del XIX venía realizando el registro cientificista de la región a través de geógrafos, antropólogos, arqueólogos, misioneros, expedicionarios y empresarios. En el contrapunto, Chambi añade el plus estético y afectivo desde el que disputa un territorio y gestiona una identidad local. En la operación logra rebasar la vieja y estereotipada oposición costa/sierra desde la cual argumentaban los sectores letrados del indigenismo. Habrá que cuidarse de reducir el análisis de sus imágenes a temas, conceptos, esquemas clasificatorios, tipos. No se trata de explicarlas sino de dar cuenta de los duelos, los desgarramientos y las tensiones que las atraviesan para, tal vez, alcanzar a percibir las voces inaudibles, los reclamos perdidos, el desafío al patrón logocéntrico que descansa en la primacía de la palabra sobre la imagen. Veamos.

Las fotografías de Chambi son bellas por el juego de contrastes, por la gama de matices, por los grados de luz

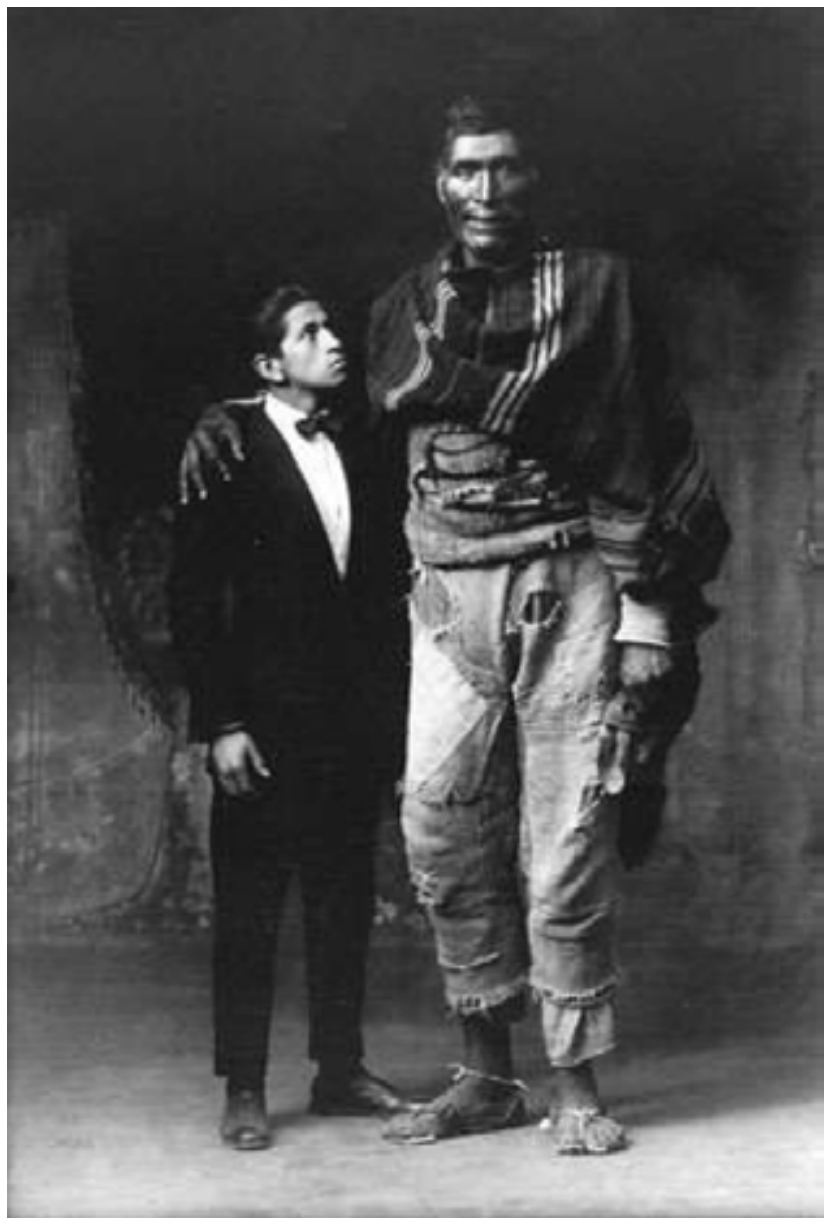

Gigante de Paruro y Víctor Mendivil. Fotografía de Martín Chambi (1925) y sombra que logran desplegar. Sus texturas, como un trompéoeil, otorgan profundidad a los pliegues de la textilería que - aun cuando son el registro de simples andrajos- articulan una semiótica de la ropa en sus retratados. El brazo protector del gigante envuelve con afecto el cuerpo del hombre de traje que se empequeñece por efecto del contraste. Esto se debe al tratamiento formal de la que es objeto la imagen. El gigante es tan monumental como el paisaje de piedra de las tomas de Machu Picchu que por ese entonces Chambi ejecutaba para las Guías de promoción del Cusco. Sus indios son de tarjeta postal, retratan la vida rural con la medida justa de inocencia y emoción. Con agudeza crítica José Carlos Huayhuaca señala que frente a la cámara de Chambi los indios terminan por adquirir un rostro poético, sufrido y hermoso. Algunas de sus escenas rozan lo melodramático, intensificando la percepción de las jerarquías y divisiones sociales. Menos que una efectiva integración de culturas, la fotografía del gigante pone en escena una situación bizarra. El indio y el mestizo anexan sus cuerpos visibles 
pero no se igualan, o mejor, hacen visible las desigualdades pero sin el esquematismo sociológico que desplegaba la narrativa indigenista por esos años. Pablo Rocca la llamó «épica de los pies». «Desnudos o mal calzados, revestidos de negro polvo o enterrados en la greda (...) las fotografías de Chambi asocian al hombre con su terruño. No es fortuito este vínculo». Pies descalzos, jirones y harapos que no se confunden con la denuncia miserabilista del realismo social. Al contrario, el grado de equilibro es tan cuidado que la pobreza se proyecta en clave barroca. Las imágenes desfiguran a sus personajes, los ex-propia para abismarlos al tiempo que territorializa sus cuerpos al trabajarlos desde los dobleces de un andrajo. Confía en el efecto que adensa las texturas otorgando patetismo a la escena. Otras veces hace relucir los ornamentos del atuendo típico. De este modo, el pliegue de la textura se resuelve en pulsión estética que resiste contra las estrategias utilitaristas del motivo folclórico, la demanda turística o la misión evangélica. El documentalismo aquí no reniega del factor estético. Más aún, Chambi documenta con curiosidad barroca las contradicciones de una sociedad basada en la exclusión y la desigualdad. Qué decir sino de los criados y siervos que suelen aparecer entre bambalinas, poniendo en escena miradas furtivas, segundos planos que vienen a disputar las jerarquías impuestas. El contraste entre la sombra y la luz es la metáfora de una sociedad tensionada por su orden estamental. ¿Cómo no estremecerse con la criada apenas visible que nos mira desde un costado en la mansión de los Montes? Como dice Julio Ramos a propósito de las fotografías de Sebastiaõ Salgado, «la estilización es central en ese imaginario alegórico que transforma la particularidad del cuerpo en emblema, cifra o referencia cultural, para incidir en un barroquismo notablemente perturbador, que por momentos, como todo barroquismo moderno, colinda con el kitsch» (Ramos:191).

La tensión barroca en la fotografía de Chambi se traduce en duelo, entendido en su doble acepción: aflicción y dolor por una pérdida y, al mismo tiempo, conflicto, combate, desafío. Un duelo asimilable a la agonía de Unamuno que fue la educación sentimental de José Carlos Mariátegui y fundamento de sus polémicas sobre indigenismo. Un duelo, un combate entre el mirante y el mirado. Se trata del carácter fantasmático de la experiencia visual que Didi-Huberman asocia con la aporía del aura, experiencia que retorna más allá de la reproductibilidad técnica de las fotografías de Chambi cuando quedamos cautivados, capturados por alguna de sus imágenes, paralizado en instancia de contemplación. Sabemos que es el valor cultual lo que le da al aura su poder. ¿Qué es un culto? En principio, cultus - del verbo latino colo- designó el acto de habitar un lugar, cultivarlo, cuidarlo. También un modo de practicar la justicia. Es decir, un acto relativo al lugar, a la tierra trabajada, o a una morada o, también, al trabajo artístico. Por eso el adjetivo cultus está vinculado al ornatus y a la cultura en el sentido estético del término. La exagerada estilización de Chambi se juega en la dialéctica entre la representación del dolor por los bienes perdidos de un pueblo que hizo y hace de la tierra un culto y el desafío que late en las miradas de aquellos que desde el pasado aún reclaman por el daño infligido.

\section{Notas}

1 La misma fotografía había sido publicada por Lunwerg en 1990 como Q’Orilasos de Chumbivilcas 1944, un título que describe con acierto a los personajes retratados. En la primera fila,

en tercer lugar de izquierda a derecha se distingue la figura de Pancho Gómez Padrón con su charango a sus pies, músico y cantante de gran popularidad en el Cusco entre 1920 y 1940 que 
también hizo giras artísticas por distintos países de América Latina, incluso en Buenos Aires.

2 El Q'orilaso de Chumbivilcas es un jinete similar al gaucho argentino que se dedica a la doma y a las carreras de caballos. Es reconocible por sus adornadas «q'arawatanas» (chaparreras) de cuero, camisa a cuadros, botas con espuelas, el sombrero blanco, poncho rojo y el siempre presente lazo dorado. Su figura alcanza tintes románticos y legendarios debido a la valentía y al carácter rebelde que lo caracteriza además de hacer un culto al amor.

3 «Inclusive más de cien años después de la Independencia, una parte amplia de la servidumbre india estaba obligada a reproducir su fuerza de trabajo por su propia cuenta» (Quijano:207).

4 Lauer introduce la fórmula «indigenismo-2» para denominar al movimiento estético-cultural que se desarrolló entre las décadas del veinte y cuarenta en Perú diferenciándolo del indigenismo sociopolítico: «El indigenismo-2 se presentó como el intento de usar la creación para explicar un mundo al otro. (...) Así, incluso antes de explicar cómo eran los condenados de la tierra peruana, el proyecto implícito fue educar a los opresores, con la esperanza de que una pedagogía exitosa — suerte de educación por el arte - curara a un país incompleto, cuya fractura emocional era de siglos. Para la definición de indigenismo-2, enredado con los datos concretos de la producción creativa misma en cuanto estilo y temperamento, es importante su actividad expositiva, es decir, su didactismo, el intento de orientar la relación de las artes y las letras a partir de una idea de lo nacional, la propuesta tácita de una justicia visual y de una justicia temática, de un restablecimiento de los fueros de los postergados» (Lauer:44-45).

5 Etnografía y fotografía, en sus respectivos orígenes, estuvieron entrelazadas ya que el surgimiento de ambas fue casi simultáneo. Demeterio Brisset Martín señala que a los dos años de la primera exposición fotográfica con la que Daguerre divulgó su invención de imágenes positivas fijas, se fundó la Sociedad para la Protección de los Aborígenes (1841), precedente del Real Instituto Antropológico de Londres. Y escasos años después ya se utilizaba el nuevo invento para fotografiar tanto a los nativos chinos (Itier en 1843) y a los indios de Estados Unidos (1847) como a los esclavos negros de Carolina del Sur (Zealy en 1850, para demostrar la inferioridad de la raza negra). En Europa, los fotógrafos ambulantes están presentes en las fiestas populares desde 1850 y poco después, en pleno período de expansión colonial, la Asociación Británica para el Avance de la Ciencia (BAAS) publicó, en 1854, un Manual para informes etnológicos, donde se imparten una serie de instrucciones para cónsules, políticos, residentes y viajeros, en las que se indica cómo deben recopilar la información de manera estandarizada sobre los diferentes tipos raciales, usos y costumbres, recomendando la obtención de retratos individuales de estas gentes, mediante procedimientos fotográficos (Brisset Martín).

6 Es el caso de las muchas fotos de artista que Chambi produjo, entre ellas, es notable la que hizo del mismo Pancho Gómez Padrón con sus instrumentos y el traje de Q'Orilaso con el que realizaba sus presentaciones.

\section{Referencias bibliográficas}

Appadurai, A. (2001). La modernidad desbordada. Dimensiones culturales de la globalización. Buenos Aires: Fondo de Cultura Económica.

Cornejo Polar, A. (1978). El indigenismo y las literaturas nacionales: su doble estatuto socio-cultural. Revista de Crítica Literaria Latinoamericana, (7), 7-21.

(1994). El indigenismo andino. En A. Pizarro, América Latina: Palabra, literatura e Cultura. Vol. II: Emancipação do Discurso. Campinas: Unicamp, 719-738.

Coronado, J. (2009). Photographs at the edge. Martín Chambi and the Limits of Lettered Culture. En The Andes imagined. Indigenismo, Society, and Modernity. Pittsburgh: University of Pittsburgh Press, 134-162.

Chambi, M. (1920-1950). Textos de Mario Vargas Llosa y Publio López Mondéjar. Barcelona: Lunwerg Editores, 1990.

Brisset Martín, D. (1999). Acerca de la fotografía etnográfica. Gaceta de Antropología, (15). http://hdl.handle. net/10481/7534 
Derrida, J. (1996). Mal de Archivo. Madrid: Trotta.

Didi-Huberman, G. (2014). Pueblos expuestos, pueblos figurantes. Buenos Aires: Manantial.

Franco, C. (1990). Impresiones del indigenismo. Hueso Húmero, (26), 44-68.

Foster, H. (1985). The «Primitive» Unconscious of Modern Art. October, (34), 45-70.

García Liendo, J. (2017). El intelectual y la cultura de masas. Argumentos latinoamericanos en torno a Ángel Rama y José María Arguedas. Indiana: Purdue University Press.

Huayhuaca, J. C. (1993). Martín Chambi, fotógrafo. Lima: Facultad de Ciencias de la Comunicación, Centro de Investigación en Comunicación Social de la Universidad de Lima, CICOSUL.

Huyssen, A. (2002). La dialéctica oculta: vanguardia-tecnología-cultura de masas. En Después de la gran división. Modernismo, cultura de masas, posmodernismo. Buenos Aires: Adriana Hidalgo, 5-40.

Lauer, M. (1997). Andes imaginarios. Discursos del indigenismo 2. Lima: Sur.

Mendoza, Z. (2006). Creary sentir lo nuestro. Folclor, identidad regional y nacional en el Cuzco, siglo XX. Lima: Fondo Editorial Pontificia Universidad Católica de Perú.

Morey, M. (2014). El lugar de todos los lugares. Consideraciones sobre el archivo. http://artarchivespolitics. com/category/miguel-morey/

Pizarro, A. (1994). América Latina: Palabra, literatura e Cultura. Vol. II. Emancipação do Discurso. Campinas: Unicamp.

Poole, D. (1991). Fotografía, fantasía y modernidad. Márgenes. Encuentro y debate, IV(8), 109-142. (1993). Figueroa Aznar y los indigenistas del Cusco: Fotografía y modernismo en el Perú de inicios del siglo XX. Márgenes. Encuentro y debate, VI(10/11), 115-170.

Quijano, A. (2000). Colonialidad del poder, eurocentrismo y América Latina. En E. Lander, compilador, La colonialidad del saber: eurocentrismo y ciencias sociales. Perspectivas Latinoamericanas. Buenos Aires: CLACSO, 201-246.

Ramos, J. (2012). Los viajes de Sebastiaõ Salgado. En Ensayos próximos. La Habana: Fondo Editorial Casa de las Américas, 174-199.

Rocca, P. T. (2015). Martín Chambi. Luz de tierra y de piedra. http://indexfoto.montevideo.gub.uy/articulo/ martin-chambi-luz-de-tierra-y-de-piedra

Schwarz, H. (2009). Martín Chambi: corresponsal gráfico. En II Coloquio Peruano de Fotografía. http:// coloquio.pucp.edu.pe/fotografia/ponencias/mesa-fotografia-e-investigacion/herman-schwarz/

Trevisan, P. y Massa, L. (2009). Fotografías cusqueñas atravesando el indigenismo. Aisthesis, (46), 39-64.

Valcárcel, L. E. (1975). Tempestad en los Andes. Lima: Universo. 